\title{
Role of Cardiolipin in Mitochondrial Diseases and Apoptosis
}

\author{
R. Santucci ${ }^{1, *}$, F. Sinibaldi ${ }^{1}$, F. Polticelli ${ }^{2,3}$ and L. Fiorucci ${ }^{1}$
}

${ }^{1}$ Department of Clinical Sciences and Translational Medicine, University of Rome 'Tor Vergata', Via Montpellier 1,
00133 Rome, Italy; ' Department of Sciences, University Roma Tre, 00146 Rome, Italy; ${ }^{3}$ National Institute of Nuclear
Physics, 'Roma Tre' Section, 00146 Rome, Italy

\begin{abstract}
Apoptosis is a highly programmed cell death strictly connected to the pathogenesis of many human diseases, including neoplastic, neurodegenerative or cardiovascular diseases. Mitochondria play a key role in the apoptotic process; their damage activates a series of events which provoke the release of cytochrome $c$ and other pro-apoptotic factors from the mitochondrial intermembrane space, and culminate in cell death. This review provides an overview of the key role played by mitochondria in the activation of the apoptotic process. In particular, the interest is focused on the role played by cardiolipin, a phospholipid deeply involved in the first steps of the process culminating in cell apoptosis. Mitochondrial phospholipids are involved in several cellular functions, such as cell respiration, apoptosis, and autophagy. Therefore, any alteration in the production of phospholipids or in their structural properties causes deep effects on the cell behavior and induces the arising of different pathologies. The present review summarizes the most recent advances in the study of the role that CL, a phospholipid possessing a unique structure, plays in mitochondrial activity, in apoptosis, and in the onset of human diseases.
\end{abstract}

Keywords: Apoptosis, Barth syndrome, cardiolipin, cytochrome $c$, mitochondrion, tBID.

\section{INTRODUCTION}

Mitochondria are present in nearly all eukaryotic cells. They contain genetic materials and enzymes important for cell metabolism, generate ATP and are involved in several other processes, such as control of the cell cycle and cell growth, cell signaling, and apoptosis [1]. Two membranes, separated by an intermembrane space, are contained by mitochondria: the outer mitochondrial membrane (OMM), which allows the transit of small molecules, and the inner mitochondrial membrane (IMM), which is arranged to form cristae. Cristae contain and organize the electron transport chain and the ATP pumps; they also separate the matrix from the space that contains protons, thus permitting the gradient needed to drive the pump. The IMM contains several proteins displaying different functions, as the redox proteins involved in the oxidative phosphorylation or the transport proteins regulating the passage of metabolites into and out of the matrix.

In cells lipids carry out different functions; they act as messengers in signal transduction, permit the aggregation (or the dispersion) of some proteins in membranes, and form cellular membranes. This last function is performed by polar lipids, which consist of a hydrophobic and a hydrophilic region. Formation of membranes is strictly linked to the tendency of the hydrophobic regions to self-associate in order to avoid any contact with water, while the hydrophilic regions tend to interact with the polar solvent. Formation of

*Address correspondence to this author at the Department of Clinical Sciences and Translational Medicine, University of Rome 'Tor Vergata', Via Montpellier 1, 00133 Roma (Italy); Tel: (+ 39) 0672596364; Fax: (+39) 0627596353; E-mail: santucci@med.uniroma2.it membranes within a cell is an important event, since it leads to formation of discrete organelles in which the internal substances are separated from the external environment.

The structure of eukaryotic membranes is mainly constituted by phosphatidylcholine (which represents approx. 50\% of the membrane phospholipids), phosphatidylethanolamine, phosphatidylserine, phosphatidylinositol, phosphatidic acid, and cardiolipin (CL, exclusively present in the mitochondrial membrane). With the exception of CL, which has a unique structure constituted by four acyl chains, the hydrophobic portion of these phospholipids is a diacylglycerol which contains saturated or cis-unsaturated acyl chains [2].

Mitochondria play a key role in activating apoptosis, a programmed cell death process in which damaged cells are removed. At the early stages of the process, proteins that normally act in the intermembrane space of mitochondria pass into the cytosol. This suggests that cell apoptosis depends on mitochondrion damage and subsequent permeabilization of the outer mitochondrial membrane (OMM), which involves the release of cytochrome $c$ (cyt c) and other proapoptotic factors from the intermembrane space [3]. In the cytosol, cyt $c$ binds to the apoptosis protease activation factor (APAf-1) to form, in the presence of ATP (or dATP), the multi-protein complex 'apoptosome'. Through the activation of pro-caspase-9 [4], the apoptosome gives rise to an enzymatic reaction cascade leading to the execution of apoptosis in cells.

Mitochondrial phospholipids are deeply involved in cell apoptosis and autophagy (a process in which damaged proteins and dysfunctional cell organelles undergo degradation $[5,6])$. Therefore, it appears clear that any alteration in the 
production of phospholipids or in their structural properties causes deep effects on the cell behavior and induces the arising of different pathologies. The present review summarizes the most recent advances in the study on the role that $\mathrm{CL}$ plays in mitochondrial activity, in cell apoptosis and in the onset of human diseases.

\section{STRUCTURE, LOCATION, AND FUNCTION}

\section{Structure}

CL (or 1,3-bis(sn-3'-phosphatidyl)-sn-glycerol) is an anionic phospholipid, first isolated from bovine heart. It is present in the cytoplasmic membrane of prokaryotes and in the inner membrane of mitochondria in eukariotes [7-10]. Whereas a number of structural analogs of the CL are found in bacteria, a single type is present in mammals; however, permutations of the four acyl chains generate several molecular species.

The unique dimeric structure of CL is shown in Fig. (1). It consists of a central glycerol linked to two non-equivalent phosphatidyl moieties, while four fatty acyl chains link via ester bond to the 1-and 2-hydroxyl groups of glycerol molecules of the polar headgroup [11]. Even with four identical acyl residues, CL shows two chemically distinct phosphatidyl moieties because the phosphate groups, each containing one acidic proton, have different chemical environments. The very different acidity of the two protons $\left(\mathrm{pK}_{1}=2.8 ; \mathrm{pK}_{2}\right.$ $>7.5$ ) affects the features of CL, which carries one negative charge around neutrality [7]. Since the secondary hydroxyl group of the central glycerol is the only hydrogen-bonding donor group in CL, the interaction with other phospholipids is unlikely. Whereas bacterial CL may contain saturated and unsaturated $\mathrm{C}_{14}-\mathrm{C}_{18}$ acyl groups, eukariotic $\mathrm{CL}$ possesses acyl chains derived from $\mathrm{C}_{18}$ fatty acids of which the linoleoyl group, which contains two unsaturated bonds, is the predominant. Tetralynoleoil CL is present in the heart, in the liver, and in the kidney; conversely, in the brain the phospholipid possesses arachidonic, docosatetraenoic, and docosahexaenoic residues [7].

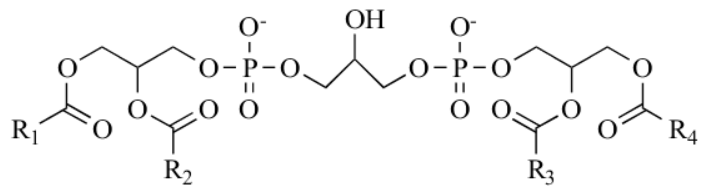

Fig. (1). Structure of CL. $R_{1}, R_{2}, R_{3}$, and $R_{4}$ represent the four acyl chains of the molecule; in most tissues, CL contains only a few dominant acyl residues, mostly 18:1, 18:2, and 18:3 fatty acids. Linoleic acid (18:2) is the most abundant (about $80 \%$ ) acyl chain in human heart mitochondria, and its presence confers to CL the well documented symmetrical profile $\left(\mathrm{L}_{4}-\mathrm{CL}\right)$.

Due to its unique (bicyclic) structure, CL undergoes structural changes; it can form micellar, lamellar and hexagonal states in aqueous dispersions, depending on $\mathrm{pH}$ and ionic strength [12]. In general, the hexagonal phase is favored by low $\mathrm{pH}$, high ionic strength, and the presence of divalent cations ( such as $\mathrm{Ca}^{2+}$ ); the lamellar phase is instead favored by some proteins. The peculiar position of CL in the inner mitochondrial membrane (IMM) is likely due to its ability to form hexagonal phases. In natural membranes, CL is generally a bilayer, with the central glycerol oriented at the water/membrane interface and the phosphatidyl moieties perpendicular to the bilayer surface; however, formation of a non-bilayer surface is possible. This event was reported to have important functional implications $[13,14]$. Due to the presence of four fatty acyl chains and a small headgroup with high $\mathrm{pK}_{\mathrm{a}}, \mathrm{CL}$ can also organize into domains having the potential to serve as a proton sink in proximity of energy transducing macromolecules [15].

\section{Location in the Mitochondrion and Interaction with Mitochondrial Proteins}

In eukaryotes, CL is mainly localized in the IMM. Its structure plays a primary role in the mitochondrion function generating, among others, an electrochemical gradient important for the production of ATP [16]. It is the only phospholipid to be synthesized in the mitochondrion rather than in the cytosolic side of the endoplasmatic reticulum $[7,17,18]$. Like the other phospholipids, CL contributes to keep the structural integrity of biological membranes; it also interacts with several mitochondrial enzymes, contributing to their correct functionality. CL acts also as a proton trap; by supplying protons for the ATP synthase, it minimizes the $\mathrm{pH}$ change caused by the large number of protons transferred across the membrane during the oxidative phosphorylation [19].

One of the most important functions of CL is its ability to interact with different proteins by non-covalent bonds $[14,18]$. CL interacts with almost all the proteins present in the inner mitochondrial membrane, including the electron transport chain complexes I, III, IV, V, involved in the oxidative phosphorilation [20-24], and the ADP-ATP carrier $[7,25]$. It also interacts with two peripherical membrane proteins: cytochrome $c$ and creatine kinase [26-29]. This attributes to CL a high degree of flexibility and an important functional role for proteins, since it facilitates a correct protein folding and contributes to the stabilization of their 'native' state $[14,30]$. These features suggest a promiscuous, rather than a markedly specific, role of CL.

The CL binding to the ADP-ATP carrier is very strong; removal of the phospholipid from the protein is observed only upon protein unfolding [31]. Not only this is in line with what stated above, i.e. that CL is critical for protein folding and stabilization, it also reinforces the view that the structural alterations of the ADP-ATP carrier observed in the absence (or in the presence of reduced levels) of CL are responsible for pathologic events, such as ischemia and heart failure, and for cell apoptosis [32,33].

The activity of complex I, complex III, and complex IV gains a remarkable benefit from the interaction with the phospholipid [20,34,35]. Interestingly, the CL binding to complex IV (cytchrome $c$ oxidase; CytcOx) is not as strong as for the ADP-ATP carrier; in this case, removal of the bound CL by other lipids does not lead to a complete loss of enzyme activity [7]. This suggests that the role played by the bound CL mainly consists in optimizing the functions of the complex. CytcOx possesses two high affinity sites for CL and other non-specific sites for phospholipids. Of the several hypotheses formulated, the one assuming that CL may favor the catalytic activity of CytcOx by modulating its conforma- 
tional transitions appears as the most reliable [36]. CL also contributes to the activity of several mitochondrial anion carrier proteins such as citrate, pyruvate, carnitine and phosphate carriers, although the mechanism of action still remains unclear [37].

\section{Favors Formation of Membrane Respiratory Super- Complexes}

One of the most important functions of CL is favoring the association of respiratory complexes into supercomplexes [34-37]. Formation of super-complexes is thought to occur in order to eliminate the diffusion of substrates among the components of the respiratory chain; this should improve the efficiency of the oxidative phosphorylation. By using site-directed mutagenesis, it was observed that the disruption of a binding site for CL in complex III alters the formation of the Cytbc1-CytcOx super-complex; the phospholipid was assigned the role to neutralize the charge of the Lys side chains located in the vicinity of the presumed domain of interaction between complex III and complex IV [38]. During formation of the respiratory super-complexes, the role played by CL differs from that of phosphatidylethanolamine, another non-bilayer-forming phospholipid present in the IMM. Destabilization of the respiratory chain supercomplexes and a decreased activity of CytcOx were observed in the absence of CL; furthermore, the inner membrane potential, $\psi$, resulted reduced. By contrast, formation of complex III-complex IV super-complexes is favored by the absence of phosphatidylethanolamine [39]. This suggests that, although both lipids are critical for the activity of the respiratory chain, the action they exert on formation of super-complexes is quite distinct. Furthermore, the recent observation that in Saccharomyces cerevisiae the supercomplex $\mathrm{III}_{2} \mathrm{IV}_{2}$ does not form in the absence of CL, highlights the primary role played by this phospholipid in the super-complexes formation process [40].

Since a correct assembly and functionality of supercomplexes require the presence of an ADP/ATP carrier protein, it has been hypothesized that one of the mechanisms by which CL favors the production of ATP consists in promoting the activity of CytcOx through the ADP/ATP carrier [33].

\section{CL and Reactive Oxygen Species (ROS) in Mitochondria}

In cells, ROS can be generated at numerous sites; however, the mitochondrial electron transport chain represents the major source of intracellular ROS. The $\mathrm{O}_{2}{ }^{-}$concentration in the mitochondrion is estimated to be up to 10 times higher than that measured in the cytosol [41]. ROS are generated, via electron transport, through a cascade of multi-enzyme complexes embedded in the mitochondrial membrane and coupled with ADP-to-ATP phosphorylation. Most of the $\mathrm{O}_{2}{ }^{-\cdot}$ produced by intact mitochondria in vitro is generated by complex I and complex III; oxidative damage to these complexes (or to the closely located electron transport complexes, as (ytcOx) is expected to inhibit electron transport. Such inhibition increases electron leakage and favors more ROS production. As recently reported, ROS and lipid peroxidation products are found to be effective inhibitors of electron-transport complexes [42].
The $\mathrm{O}_{2}$-to- $\mathrm{H}_{2} \mathrm{O}$ reduction process is a four-step reaction of sequential single electron additive processes. The several redox centers involved in the process may leak electrons to $\mathrm{O}_{2}$. In addition to the superoxide radical anion $\mathrm{O}_{2}{ }^{-}$(produced by the one-electron reduction of the $\mathrm{O}_{2}$ generated in the process), they include the hydrogen peroxide produced by dismutation of the superoxide anion and the highly reactive hydroxyl radical $(\mathrm{HO} \bullet)$. The process proceeds as shown in the following scheme:

a) $\mathrm{O}_{2}+\mathrm{e}^{-} \rightarrow \mathrm{O}_{2}{ }^{-}$

b) $\mathrm{O}_{2}^{-{ }^{*}}+2 \mathrm{H}^{+}+\mathrm{e}^{-} \rightarrow \mathrm{H}_{2} \mathrm{O}_{2}$

c) $\mathrm{H}_{2} \mathrm{O}_{2}+\mathrm{e}^{-} \rightarrow \mathrm{OH}^{-}+\mathrm{HO}^{\circ}$

Under conditions stimulating NO production [43], $\mathrm{O}_{2}{ }^{-}$ may react with nitric oxide to form the toxic peroxynitrite anion $\left(\mathrm{ONOO}^{-}\right)$, a highly reactive nitrogen species (RNS). Several efficient enzymatic processes work together to quench ROS and RNS; species involved are superoxide dismutase, catalase, peroxiredoxin, thioredoxin/thioredoxin reductase, and glutathione peroxidase [44-46]. Ubiquinone, which links complex I and complex II with complex III in the mitochondrial respiratory chain, appears to be deeply involved in the $\mathrm{O}_{2}^{-{ }^{-}}$formation. The electrons accepted by cyt $c$ from superoxide anion radicals can be released to complex IV [47]; this suggests that cyt $c$ may act as a component of the enzymatic antioxidant system of mitochondria. Support to this view comes from the observation that the cyt $c$ mediated electron-leak pathway regulates the $\mathrm{H}_{2} \mathrm{O}_{2}$ concentration in the cell $[47,48]$.

Oxidative damage is responsible for various pathological conditions and aging [59-54]. The interaction between ROS and several macromolecules causes mitochondrial dysfunction and may lead to cell death. ROS have been associated with a number of disorders; among others, ischemia injury, Parkinson's disease, and Alzheimer's disease. Peroxidation of membrane phospholipids represents a major cause for mitochondrial dysfunction, since it alters membrane permeability [55]. In particular, CL is influenced by ROS-induced damage, since the unsaturated fatty acid (particularly linoleic and docosanoic) chains in its structure are affected by oxidation [18]. CL represents an ideal target for ROS attack, being located in the IMM not far from the site where ROS production occurs. Recent studies have associated the development of heart failure with loss of tetralinoleoyl CL [56,57]; other reports correlated mitochondrial dysfunction in brain aging with CL oxidation [58].

\section{BIOSYNTHESIS AND REMODELING}

\section{Biosynthesis}

The biosynthetic pathway of CL is similar to that of other phospholipids in that it proceeds through several steps of modifications of phosphatidic acid (PA). A scheme for CL biosynthesis and remodeling is reported in Fig. (2). In eukaryotic cells (yeasts, plants and animals), $\mathrm{CL}$ is synthesized with in the mitochondrion, where it is exclusively utilized. The first committed step in CL biosynthesis is the formation of phosphatidylglycerolphospha (PGP). Such synthesis proceeds through the conversion of $\mathrm{PA}$ to cytidine diphosphate-diacylglycerol (CDP-DAG) 
and is catalyzed by CDP-DAG synthase (CDS), an enzyme which operates in multiple phospholipid-synthetic pathways. CDS is conserved from bacteria to human and it is localized in both the endoplasmic reticulum and mitochondria [59]. It has been recently observed the presence of a further CDP-DAG synthase (named Tam41) in mitochondria, operating exclusively in the CL biosynthesis pathway [60]. In turn, CDP-DAG reacts with glycerol3-phosphate (G3P) to form PGP through the action of the PGP synthase (PGPS) [61,62]. In mammals, PGP is dephosphorylated to phoshatydylglycerol (PG) by a protein tyrosine phosphatase localized in the mitochondrion, the protein tyrosine phosphatase mitochondrial 1 (PTPMT1). The critical function of this phosphatase seems to consist in the modulation of CL biosynthesis via the phosphatidylglycerol level [63]. Since perturbations in CL levels have been associated with apoptosis and the block of apoptosis is considered to be a hallmark of cancer, the dysregulation of CL homeostasis may affect both the ability of cells to undergo cell death and their tumorigenic potential. Indeed, recent studies indicate that the downregulation of PTPMT1 induces mitochondrialdependent apoptosis in cancer cells and renders them sensitive to chemotherapeutic treatment [64]. Interestingly, inhibition of the PTPMT1 function causes a shift to glycolysis, perhaps for counterbalancing the mitochondrial bioenergetic impairment associated with CL dysregulation.

The cardiolipin (or diphosphatidylglycerol) synthase, a phosphatidyl transferase, links the phoshatidyl group of CDP-DAG to PG, with elimination of cytidinmonophosphate (CMP) and formation of CL. The eukaryotic cardiolipin synthases show a $\mathrm{pH}$ optimum $(\mathrm{pH} 8-9)$, requirement for specific divalent cations $\left(\mathrm{Mg}^{2+}, \mathrm{Mn}^{2+}\right.$, or $\left.\mathrm{Co}^{2+}\right)$ and little, if any, acyl chain specificity. Immature CL is characterized by saturated acyl chains of variable length and asymmetry about the central carbon of the bridging glycerol $[14,65]$. In rat liver, the cardiolipin synthase resides in the inner mitochondrial membrane with its catalytic center exposed to the matrix side of the inner membrane [65].

\section{Remodeling}

In mature CL, the final acyl chain composition consists of unsaturated fatty acids obtained through deacylationreacylation/transacylation reactions, a process commonly referred to as CL remodeling. In mammals, CL deacylation is initiated by a calcium independent phospholipase A2 $\left(\mathrm{iPLA}_{2} \gamma\right)$ [66]. Such phospholipase removes one saturated fatty acyl chain forming monolysocardiolipin (MLCL). MLCL is then reacylated by the transacylase tafazzin (Taz1) to form mature CL. While synthesis of immature CL is on the matrix-facing leaflet of the inner membrane, Taz1 associates with intermembrane space-facing membrane leaflets. Thus MLCL generated by phospholipase must be transported to the intermembrane space-facing membrane leaflets to gain access to Tazl by means of a scramblase or other transporters.

This step seems to be the major site of regulation in CL remodeling. In heart mitochondria, tafazzin is known to transfer with high selectivity linoleate groups from phosphatidylcholine (PC) to monolysocardiolipin, promoting molecular symmetry among the molecular species of $\mathrm{CL}$ acylated at all four positions (with formation of lysophosphatidylcholine) $[67,68]$. There is evidence that the acyl specificity of tafazzin does not reside in the enzyme itself but on the physical properties of the membrane domain in which transacylation reactions take place. The reaction of tafazzin is responsive to the phase state of the membrane and the molecular species of cardiolipin synthesized are those that favor membrane curvature [69].

Further enzymes in mammalian cells have the ability to attach an acyl chain to monolysocardiolipin, i.e. monolysocardiolipin acyltransferase-1 (MLCLAT1), that shows specificity for linoleate, and an acylCoA:lysocardiolipin acyltransferase-1(ALCAT1) which has a coenzyme A (CoA)-dependent mechanism and shows no specificity for linoleic acid. Strikingly, the latter enzyme catalyzes the incorporation of long polyunsaturated fatty acyl chains. Overexpression of this enzyme seems to have a negative role on CL biosynthesis in that makes CL particularly prone to ROS-mediated peroxidation while alterations in the MLCLAT expression level affect the incorporation of $\left[{ }^{14} \mathrm{C}\right]$ linoleic acid into cardiolipin [70]. It has been shown that expression of acyltransferase enzymes is altered in pathological conditions, such as cardiomyopathy and diabetes [71-73]

Beyond Taz1, MLCLAT1 and ALCAT1, a further CL remodeling enzyme has been recently characterized. It is identical to the alpha subunit of trifunctional protein ( $\alpha$ TFP) devoid of the first 227 amino acids and it is endowed of MLCL acyltransferase activity [74]. TFP is a key protein in $\beta$-oxidation of long chain fatty acids, and the finding further links the process of energy production in mitochondria to $\mathrm{CL}$ remodeling.

Despite the presence of CL on both leaflets of the IMM and also to some extent in the outer membrane [75], newly synthesized CL is produced within the matrix-facing leaflet of the IMM [76,77]. Thus, the final product must be transported by appropriate mechanisms to its final membrane destination. Two mechanisms have been suggested to govern CL transport; one involves a phospholipid scramblase-3 (PLS-3), expected to facilitate accumulation of CL in the outer mitochondrial membrane [78], the other involves a mitochondrial creatine kinase localized in the intermembrane space, which is assumed to transfer lipids between membranes [79].

\section{Pathological States Associated with Altered CL Metabo- lism}

In light of its importance in cellular and mitochondrial activities, perturbations in CL synthesis and/or remodeling are associated with a plethora of human disorders. Changes in enzymes involved in the CL biosynthesis and remodeling by human disorder, are reported in Fig. (2).

In most tissues, CL contains only a few dominant acyl residues, mostly 18:1, 18:2, and 18:3 fatty acids. Linoleic acid (18:2) is the most abundant (about $80 \%$ ) acyl chain in human heart mitochondria, and its presence confers to $\mathrm{CL}$ the well documented symmetrical profile $\left(\mathrm{L}_{4}-\mathrm{CL}\right)$ [67]. At variance, brain contains a substantially more complex fatty acid chain profile with over $100 \mathrm{CL}$ molecular species characterized by the increased presence of signaling fatty 
acids (i.e. arachidonic acid and docosahexaenoic acids) and a lower symmetrical profile [80]. It is likely that different and asymmetrical CL molecular species in brain tissue reduce mitochondrial bioenergetic efficiency but, since brain utilizes glucose in the glycolysis as the major source of energy, electron-transport chain efficiency is not a limiting factor for energy production $[81,82]$. Thus, in last years it has been proposed that changes in the levels and species of CL affect not only mitochondrial function, but also signaling networks [71]. Intriguingly, a role for CL as signaling molecule has been proposed in neuronal cells [83]. The authors demonstrated that externalization of CL from inner mitochondrial membrane to the outer mitochondrial membrane occurs in challenged neurons. This event likely acts as an elimination signal of damaged mitochondria [83]. Recognition of injured mitochondria and their degradation (mitophagy) is fundamental for cellular health, and dysregulation of cell quality control in neurons is implicated in neurodegenerative diseases and ageing [84]. Hallmarks of Alzheimer's and Parkinson's diseases are formation of misfolded protein and peptide aggregates (amyloids) that progressively accumulate into neurons [85-88]. Amyloid aggregates interact with mitochondrial membranes, inducing their permeabilization and triggering the cytochrome $c$ release [86-89]. Interestingly, such an effect on mitochondria seems to be CL-dependent [89]. The CL affinity for amyloid aggregates induces membrane destabilization, and it makes CL a specific crucial factor in the targeting of the inner mitochondrial membrane, by aggregation-prone proteins and peptides. Furthermore, peroxidation of the CL interacting with (partially unfolded) cyt $c$ is an early trigger of apoptosis [90-92]. Intriguingly, minocycline, an antibiotic known as a neuroprotective agent delaying progression of neuron degeneration, behaves as inhibitor of the peroxidase activity of cyt $c$ on CL in vitro [93]. Due to numerous structural and biochemical abnormalities occurring in tumor cell mitochondria, cancer cells rely on glucose utilization and increase of glycolytic fluxes under aerobic conditions for energy production (the "Warburg" effect $[94,95]$ ). Indeed, some authors reported that major abnormalities in CL content or composition were found in some brain tumors, i.e an abundance of immature molecular species and deficiencies of mature molecular species [80,96]. Interestingly, CL content was significantly increased and a change in fatty acid composition was found in liver mitochondria during cancer cachexia, suggesting defects in CL synthesis and remodeling, able to influence ATP production efficiency and energy wasting in liver mitochondria in cancer cachexia syndrome [97].

In humans, tafazzin deficiency causes Barth syndrome, an X-linked inherited infantile disease characterized by dilated cardiomyopathy, skeletal muscle weakness, growth retardation and neutropenia [98-100]. Mitochondria from patients with Barth syndrome have an increased MLCL content, a CL content lower than that present in control cells, and display changes in acyl chain composition resulting in the loss of $\mathrm{L}_{4}$-CL. It remains unclear how abnormal CL homeostasis actually plays a role in the pathogenesis of Barth syndrome.

By measuring the activity of respiratory enzymes and by electron micrographs, it was demonstrated that the disease has a profound impact on structure and function of mitochondria [100]. Isolated mitochondria from patient's cells display lower rates of coupled respiration as compared to mitochondria from cells from normal individuals. Upon CL content decrease, the generation of ROS is enhanced. ROS in turn cause peroxidation of the CL unsaturated fatty acids. Compromised CL synthesis or CL oxidation seem to be primary features of aging. In aging cells, CL is pathologically remodeled with polyunsaturated fatty acids instead of linoleic acid present in normal CL [101]. Perturbations in CL content and acyl composition have been also described in heart failure (HF) [56].

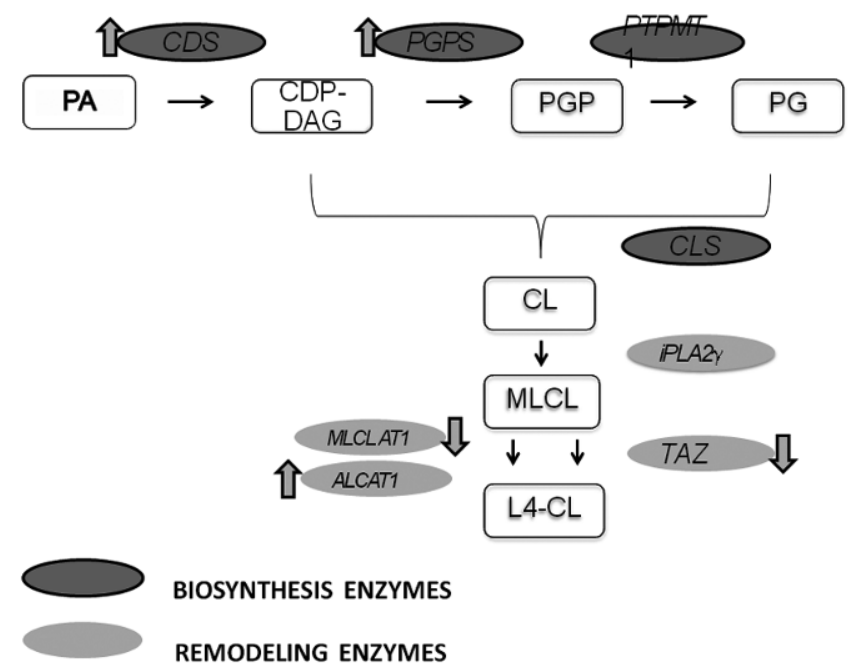

Fig. (2). The scheme reports the changes in CL biosynthesis and remodeling enzymes in human disorders. The arrows indicate general changes to the enzyme. ALCAT $\mathrm{AL}_{1}$, acyl-CoA:lysocardiolipin acyltransferase-1; CDP-DAG, cytidinediphosphate diacylglycerol; CDS, cytidinediphosphatediacylglycerol synthetase; CL, cardiolipin; $\mathrm{L}_{4}$-CL, tetralinoleoyl CL; CLS, cardiolipin synthase; MLCL, monolysocardiolipin; MLCL $\mathrm{AT}_{1}$, MLCL acyl transferase; PA phosphatidic acid; PG, phosphatidyl glycerol; PGP, phosphatidylglycerolphosphate ; PGPS, PGP synthase; $\operatorname{iPLA}_{2} \gamma$, calcium independent phospholipase A2; PTPMT1, protein tyrosine phosphatase, mitochondrial 1; TAZ, tafazzin.

In particular, the mitochondrial CDP-DAG synthase activity increase observed during HF development may be related to the increased secretion of inflammatory mediators, (i.e. tumor necrosis factor- $\alpha$, and interleukin-6) which are known to cause contractile dysfunction [71]. Also the PGPS enzyme activity, which is responsible for condensation of CDP-DAG with glycerol-3-phosphate to form PG-phosphate (PGP), increases and the protein seems to be posttranslational modified during the development of HF [71]. CLS enzyme activity and its mRNA expression were decreased during the development of HF in rats but not in humans.

An alternative form of CL remodeling during the development of HF brings about an increase of the CL species containing oleic acid (18:1), arachidonic acid (20:4), and docosahexaenoic acid (22:6) with respect to the normal levels. It has been suggested that alterations in functional tafazzin gene expression may contribute to HF in the absence of Barth Syndrome [71]. 


\section{AND APOPTOSIS}

\section{Cell Apoptosis: Key Role of the CL-Cytochrome $c$ Inter- action}

As described in the 'Introduction' section, mitochondria are deeply involved in cell apoptosis. The increase of mitochondrial permeability occurring during the process, leads to the release of a number of mitochondrial proteins into the cytosol [102]. In particular, release of cyt $c$ has been attributed to the formation of the mitochondrial apoptosis-induced channel (MAC, formed by Bax and/or Bak, see below) in the outer mitochondrial membrane [103]. The pro-apoptotic activity of cyt $c$ is strictly correlated with that of CL, the molecular target of tBID, a Bcl-2 family protein which promotes the apoptosis at the mitochondria [104-106].

Cyt $c$, whose structure is shown in Fig. (3), plays a key role in initiating the apoptotic process. In healthy cells, the protein works in between the inner and the outer membrane, mediating electron transfer (eT) between different proteins of the respiratory chain [107]. Free and loosely bound cyt $c$ (about $85 \%$ ) contributes to eT, inhibits ROS formation, and prevents oxidative stress; conversely, the protein tightly bound to the IMM (15\%) accounts for peroxidase activity, an event crucial for initiating apoptosis [108-110]. The cyt $c$ $\mathrm{CL}$ interaction plays a key role in determining the cell fate; at the early stage of apoptosis, peroxidation of the CL interacting with (the partially unfolded) cyt $c$ acts a trigger of the process [111-113]. The cyt $c$-CL interaction decreases, thus favoring cyt $c / \mathrm{CL}$ complex dissociation and the release of free cyt $c$ into the cytosol $[110,114]$.

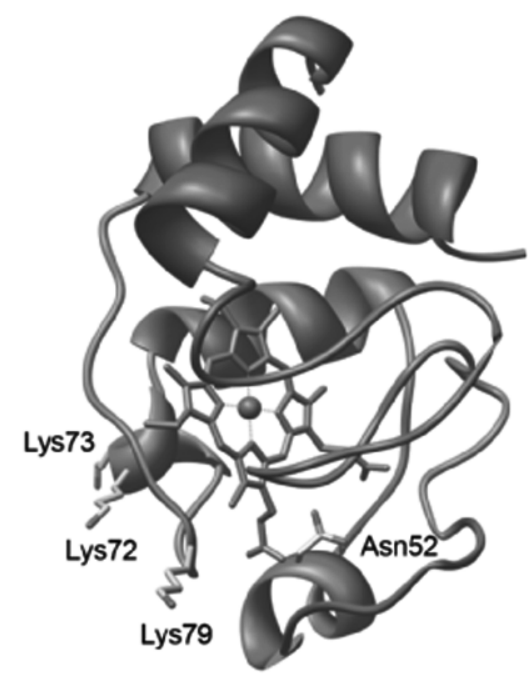

Fig. (3). Ribbon structure of cyt $c$. The protein structure was visualized with Swiss-Pdb [143].

In cells, CL binding to cyt $c$ occurs at two distinct protein sites, the A-site and the $\mathrm{C}$-site, which are characterized by different affinity for the phospholipid [26,115]. The A-site, constituted of basic residues (possibly Lys72 and Lys73), is of electrostatic nature, while the C-site is hydrophobic. Upon cyt $c / \mathrm{CL}$ complex formation, at level of the C-site one acyl chain of CL was initially proposed to accommodate into the protein while the other one points to the opposite direction from the headgroup [27,116]. Two different regions of the protein were proposed to host the acyl chain of CL: a hydro- phobic channel close to the invariant Asn52 residue [112], and the region containing a network of positively charged residues located in the heme-binding region (Lys72, Lys73, and Lys86) [27]. In the latter case, the cleft formed by the Lys residues is the site expected to be involved in the penetration of the acyl chain into the protein until it reaches the heme pocket region. However, in both cases the lipid anchorage to cyt $c$ does not result optimal because the insertion of a single chain into the protein would cause partial exposure to the solvent of (at least) one of the other three adjacent acyl chains embedded in the membrane, a situation which is not favored from a solvation energy viewpoint. Thus, a new model has been recently proposed which assumes that two (instead of one) adjacent acyl chains of the membrane protrude into the same cyt $c$ molecule to form the cyt $c / \mathrm{CL}$ complex, as illustrated in Fig. (4), in an event undoubtedly more favored from a stereochemical viewpoint [117]. To date, the location on the protein of the site(s) hosting CL insertion remains uncertain. By site directed mutagenesis, it has been recently shown that the conservative Arg91 residue, which anchors the cleft constituted by residues 67-71 and 8285 , plays a critical role in affecting the structural and ligandexchange properties of the $\mathrm{Fe}(\mathrm{II}) \mathrm{cyt} c / \mathrm{CL}$ complex [118]. It was also proposed the existence of a distinct binding site, constituted by the Lys22, Lys27, Lys33 and Lys87 residues and called the L-site, located at the opposite side of the macromolecule with respect to the A-site. The L-site, which appears to be active at $\mathrm{pH}$ lower than 7.4, seems to play a role in bringing two lipid vesicles together by the same protein molecule, for fusion [119]. Furthermore, a very recent study on the cyt $c / \mathrm{CL}$ complex has revealed the existence of a multitude of CL-bound cyt c conformations differing for their degree of unfolding; this suggests that CL can modulate, through interactions of electrostatic nature, the unfolding of cyt c $[120,121]$.

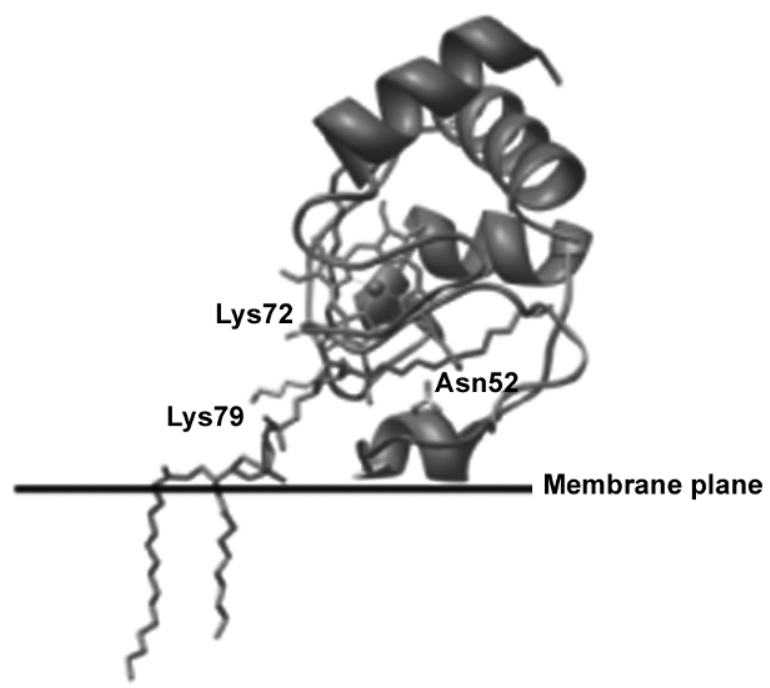

Fig. (4). The $\mathrm{CL} / \mathrm{cyt} c$ complex showing the acyl chain binding sites within cyt $c$.

Despite the different hypotheses formulated to date and the uncertainty still pending on the cyt c/CL binding process, what is undoubtedly ascertained is that cyt $c$ undergoes tertiary changes upon cyt $c / \mathrm{CL}$ complex formation; such changes imply a slight decrease of the $\alpha$-helix content, perturbation of 
the $\operatorname{Trp} 59$ microenvironment, the displacement of Met80 from the axial position of the heme iron and (depending on $\mathrm{pH}$ and ionic strength) a change of the spin state of the metal [26-28, 115-119].

\section{Cyt c/CL Complex Dissociation and CL Peroxidation: The Key Steps for Initiating Apoptosis}

Cyt $c$ released in the cytosol plays a key role in the initiation of the apoptotic process; it activates caspase-9, one of the proteases involved in the caspase cascade leading to apoptosis. To achieve cyt $c$ release from the mitochondrion, the cyt $c / C L$ complex must undergo dissociation. CL peroxidation is one of the factors considered responsible for such event to occur, although the mechanisms favoring complex dissociation still remain unclear. This is based on the evidence that CL hydroperoxides have significantly reduced binding affinity for cyt $c$ with respect to CL itself $[111,122]$, and on the observation that CL peroxidation is prevented by Bcl-2, the protein member of the Bcl-2 family which inhibits cyt $c$ release from mitochondrion [123].

At the mitochondrial stage of apoptosis, cyt $c$ drives the oxidation of protein and lipid substrates and the accumulation of membrane phosholipid hydroperoxides, particularly CL hydroperoxides $[112,123]$. As a heme-protein, cyt $c$ may be in fact converted into a peroxidase, although under normal conditions the peroxidase activity of cyt $c$ is extremely low $[124,125]$ (the peroxidase activity of cyt $c$ is induced by post-translational modifications caused by the cyt $c$-CL binding $[93,112,117]$, which weakens the Fe(III)-Met80 axial bond, increases the heme accessibility to $\mathrm{H}_{2} \mathrm{O}_{2}$, and favors activation of the peroxidase function of the protein $[27,28,93,115])$. These events facilitate the detachment of cyt $c$ from the IMM, through formation of the PTP. Recent studies have shown that CL oxidation mobilizes not only cyt $c$ but also CL itself as a hydroperoxide species. By translocating to the outer membrane, the hydrophilic hydroperoxides may promote the action of the pro-apoptotic proteins tBID and Bax for the generation of cyt $c$-permeable pores. tBID was found to bind more promptly to $\mathrm{CLOOH}$-containing membranes than to CL- containing ones [126].

The catalytic mechanism of formation of a highly oxidized heme in the cyt $c / C L$ complex in the presence of $\mathrm{H}_{2} \mathrm{O}_{2}$ is illustrated in Fig. (5); it implies the subtraction of one electron from unsaturated acyl chains of CL and formation of a lipid hydroperoxide. The newly formed lipid hydroperoxides may function as substrates for the peroxidase activity of cyt $c$, and propagate lipid peroxidation even in the absence of $\mathrm{H}_{2} \mathrm{O}_{2}$. The selective oxidation directed toward $\mathrm{CL}$ triggers the release of cyt $c$ from the mitochondrion and activates the intrinsic cell death pathway. CL-bound cyt $c$ cannot convert $\mathrm{O}_{2}{ }^{-\bullet}$ into $\mathrm{O}_{2}$ and lacks the superoxide-scavenging antioxidant function described above [127]. Under 'normal' conditions the CL-bound cyt $c$ favors, through an antioxidant function, the removal of the $\mathrm{H}_{2} \mathrm{O}_{2}$ formed in mitochondria; conversely, during the cell-death pathway the role of the (cyt $c$-CL) complex changes, initiating a pro-oxidant activity in which it oxidizes CL as preferential substrate.

From the disruption of the electron transport chain during apoptosis, it results that the enhanced production of superoxide and dismutation yields $\mathrm{H}_{2} \mathrm{O}_{2}$. This drives the peroxidase reaction of the cyt $c / C L$ complex, with subsequent CL oxidation. Clearly, the prevention (or inhibition) of $\mathrm{H}_{2} \mathrm{O}_{2}$ production would inhibit the peroxidase-catalyzed CL oxidation. As recently reported, dopamine, L-DOPA, or minocycline,

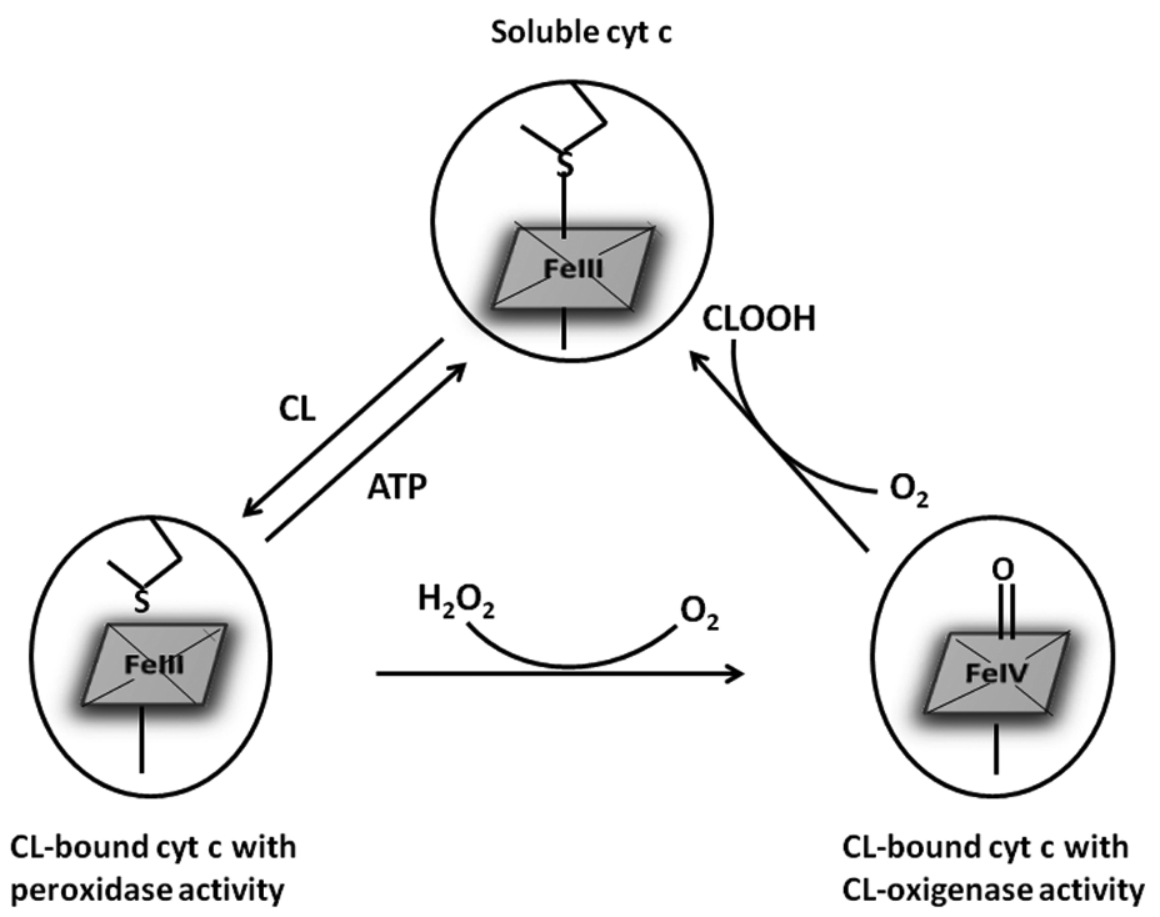

Fig. (5). Cyt $c$ activity as a peroxidase. The cyt $c$-CL interaction converts cyt $c$ to a peroxidase, destabilizing the tertiary structure and inducing the rupture of $\mathrm{Fe}(\mathrm{III})-\mathrm{Met} 80$ axial bond. ATP binding to the protein reverts such conformational change. $\mathrm{H}_{2} \mathrm{O}_{2}$ induces the synthesis of oxoferryl $\mathrm{Fe}(\mathrm{IV})=\mathrm{O}$ form of cyt $c$ and the subsequent oxygenation of $\mathrm{CL}$ to $\mathrm{CL}$ hydroperoxide (CL-OOH) causes cyt $c / \mathrm{CL}$ complex dissociation. 
compounds exerting an attenuating effect on the progression of some neurodegenerative diseases (including Parkinson's disease), inhibit the peroxidase activity of cyt $c$ [128].

Regulation of the CL peroxidation may represent a novel strategy in anti- (or pro-) apoptotic drug discovery. The synthesis of highly oxidizable CL may favor the development of antitumor therapies opposing the common resistance of tumor cells to pro-apoptotic drugs, while dietary manipulation may lead to non-oxidizable molecular forms of CL, thus protecting cells from apoptosis [129].

\section{Cyt $c$ Release from Mitochondria. Role of the CL-tBID Interaction}

The Bcl-2 family proteins, which regulate the OMM permeabilization, are divided into three main groups: the anti-apoptotic Bcl-2 members (Bcl-2, Bcl-X $\mathrm{L}, \mathrm{MCL}-1)$, the pro-apoptotic multi-domain members (Bax, Bak, BOK), and the $\mathrm{BH} 3$-only pro-apoptotic proteins (BAD, BID, BIM) [130]. These molecules associate via their $\mathrm{BH}$ domains, forming homo- or hetero-complexes, and play different roles in the OMM permeabilization process. Bax and Bak are responsible for the disruption of the OMM integrity, since they induce OMM permeabilization. Such a role is highlighted by the observation that double-deficient cells do not undergo apoptosis [4,6,104,131,132]. BID represents an important link between extrinsic and intrinsic apoptotic pathways. The starting point for the extrinsic pathway requires engagement of plasma membrane death receptors and formation of the death-inducing signalling complex (DISC), a platform responsible for the activation of initiator caspases, such as caspase 8 [133]. Once activated, caspase 8 cleaves other substrates, including caspase 3 , leading to cell death. In some cell types, this direct route is not strong enough to fully induce apoptosis; the necessary amplification of the death signal is achieved by utiliz- ing the mitochondrial pathway. Indeed, once activated, caspase 8 can also cleave the $\mathrm{BH} 3$-only protein BID into the $\mathrm{p} 7$ and tBID fragments [134].

The CL located at the contact sites between outer and inner membranes represents the target of tBID, the protein appointed to the apoptotic message transmission [134]. During translocation into the mitochondrion, where it promotes the release of cyt $c[132,135]$, the tBID fragment remains in close contact with $\mathrm{p} 7$. The two fragments interact by strong hydrophobic interactions until the complex reaches the membrane. Here, tBID first alters the structure of the mitochondrion by binding to CL via its alphaH6 helix (with disruption of the mitochondrion bioenergetics); successively, in cooperation with $\mathrm{CL}$, it induces the Bax/Bak oligomerization (a process requiring the $\mathrm{BH} 3$ domain of $\mathrm{tBID}$ ), which initiates the mitochondrion disruption [136,137]. These two important steps highlight the bifunctional character of tBID. It has been recently hypothesized that tBid undergoes multiple conformational changes at the membrane, to activate Bax. Such structural rearrangements seem to represent a critical step for the OMM permealization [132]. tBID activates Bax and induces OMM permeabilization, cristae remodeling, and maximal cyt $c$ release $[104,135]$. During cristae remodeling, the structural reorganization of the inner mitochondrion membrane (IMM) allows the access of cyt $c$ to the intermembrane space, as illustrated in Fig. (6).

Recent studies suggest that the interaction of tBID with CL may not require the support of other pro-apoptotic proteins to decrease the membrane integrity [138]. The importance of the CL-tBID interaction is also highlighted by the observation that the binding of tBID to the mitochondrion significantly decreases in CL-deficient cells [139]. The tBID-CL interaction also plays a critical role in cristae remodeling and in the formation of fission sites in the mitochondrion; note that cristae remodeling is critical for the

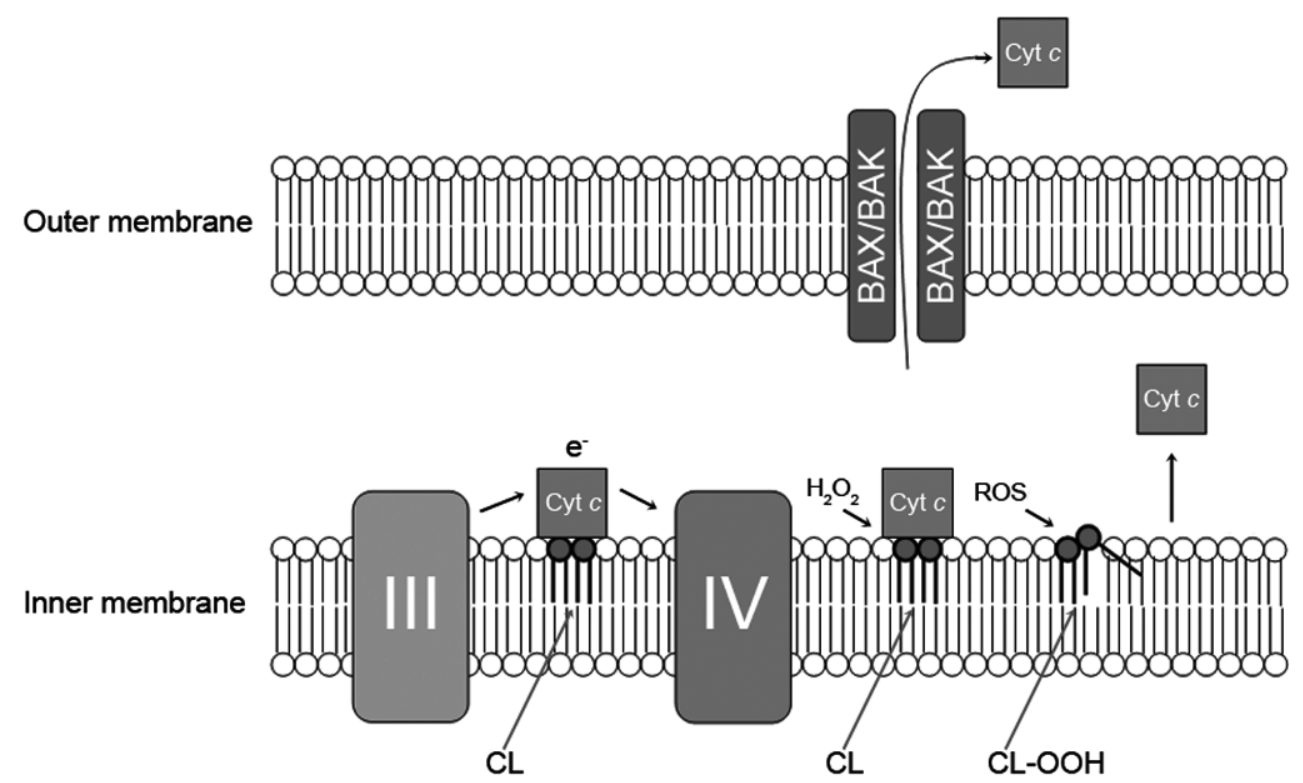

Fig. (6). Release of cyt $c$ from the mitochondrion. The tBID-promoted oligomerization of BAX gives rise to formation of pores. During apoptosis cyt $c$, which is bound to CL in the IMM under normal conditions, detaches from the phospholipid, diffuses as a free macromolecule in the intermembrane space, and is released into the cytoplasm. The process is initiated by the oxidation of CL to CL hydroperoxide (CL-OOH), caused by the cyt $c$ peroxidase activity or by ROS forming in the respiratory chain (see text, for further details). 
release of cyt $c$ into the cytosol and the proceeding of the apoptotic process $[140,141]$.

Finally, the critical role played by $\mathrm{CL}$ in the outer membrane permeabilization is pointed out by the recent finding that the presence of CL is necessary to Bax for binding to membrane-bound tBID and for penetrating into the membrane, where (through its oligomerization) it is likely to induce membrane permeabilization [142].

\section{PERSPECTIVES}

To date, many aspects of the mitochondrial-mediated cell apoptosis still remain unclear. Among others, the knowledge of CL metabolism represents a fundamental acquisition for comprehension of its contribution to health and disease. Many questions remain to be solved about the importance of this signature phosholipid for the mitochondrial function. It has been recently acquired that changes in the content, fatty acid composition and peroxidation of CL occur in a variety of pathologies and have been implicated in mitochondrial dysfunction in several tissues.

These new findings offer hints about possible treatments of diseases associated with mitochondrial dysfunction arising from the compromised CL metabolism, including heart failure, BTHS, neurological diseases, and aging. Extremely exciting is the role of CL-cyt c interaction in mitochondriadependent apoptosis. Such an interaction may represent an important target system for the development of new drugs able to regulate neuron apoptosis in neurodegenerative diseases and induce apoptosis in tumor cells. In this regard, recent findings have suggested that dysregulation of CL homeostasis may affect both the ability of cells to undergo cell death and their tumorigenic potential. Indeed, it seems of relevance to address regulation of enzymes involved in CL metabolism to induce mitochondrial-dependent apoptosis in cancer cells, and/or synthetize them to chemotherapeutic agents.

\section{CONFLICT OF INTEREST}

The authors confirm that this article content has no conflict of interest.

\section{ACKNOWLEDGEMENTS}

Declared none.

\section{ABBREVIATIONS}

$$
\begin{array}{ll}
\text { ALCAT1 } & =\text { Acyl-CoA:lysocardiolipin acyltransferase-1 } \\
\alpha \mathrm{TFP} & =\text { Alpha subunit of trifunctional protein } \\
\mathrm{APAf}-1 & =\text { Apoptosis protease activation factor } \\
\mathrm{iPLA}_{2} \gamma & =\text { Calcium independent phospholipase A2 } \\
\mathrm{CL} & =\text { Cardiolipin } \\
\mathrm{CL}-\mathrm{OOH} & =\text { Cardiolipin hydroperoxidase } \\
\mathrm{CLS} & =\text { Cardiolipin synthase } \\
\mathrm{CoA} & =\text { Coenzyme A } \\
\mathrm{CMP} & =\text { Cytidinmonophosphate } \\
\mathrm{CDP}-\mathrm{DAG} & =\text { Cytidine diphosphate-diacylglycerol }
\end{array}
$$

$\begin{array}{ll}\text { CDS } & =\text { Cytidine diphosphate-diacylglycerol synthase } \\ \text { cyt } c & =\text { Cytochrome } c \\ \text { Cytbc1-CytcOx super-complex } & \text { bc1-cytochrome c oxidase super complex } \\ \text { CytcOx } & =\text { Cytochrome } c \text { oxidase } \\ \text { eT } & =\text { Electron transfer } \\ \text { G3P } & =\text { Glycerol-3-phosphate } \\ \text { HF } & =\text { Heart failure } \\ \text { IMM } & =\text { Inner mitochondrial membrane } \\ \text { MAC } & =\text { Mitochondrial Apoptosis-Induced Channel } \\ \text { MLCL } & =\text { Monolysocardiolipin } \\ \text { MLCLAT1 } & =\text { Monolysocardiolipin acyltransferase-1 } \\ \text { OMM } & =\text { Outer mitochondrial membrane } \\ \text { PTP } & =\text { Permeability transition pore } \\ \text { PA } & =\text { Phosphatidic acid } \\ \text { PC } & =\text { Phosphatidylcholine } \\ \text { PG } & =\text { Phosphatidyl glycerol } \\ \text { PGP } & =\text { Phosphatidylglycerolphosphate } \\ \text { PGPS } & =\text { Phosphatidylglycerolphosphate synthase } \\ \text { PGPS } & =\text { Phosphatidylglycerolphosphate synthase } \\ \text { PLS-3 } & =\text { Phospholipid scramblase-3 } \\ \text { PTPMT1 } & =\text { Protein tyrosine phosphatase mitochondrial 1 } \\ \text { RNS } & =\text { Reactive nitrogen species } \\ \text { ROS } & =\text { Reactive oxygen species } \\ \text { L } 4 \text {-CL } & =\text { Tetralinoleoyl CL } \\ \text { Taz1 } & =\text { Transacylase tafazzin } \\ \text { PTPMT1 } & =\text { Tyrosine phosphatase mitochondrial 1 } \\ & \end{array}$

\section{REFERENCES}

[1] McBride, H.M.; Neuspiel, M.; Wasiak, S. Mitochondria: more than just a power house. Curr. Biol., 2006, 16, R551-R560.

[2] van Meer, G.; Voelker, D.R.; Feigenson, G.W. Membrane lipids: where they are and how they behave. Nat. Rev. Mol. Cell. Biol., 2008, 9, 112-124.

[3] Ott, M.; Zhivotovsky, B.; Orrenius, S. Role of cardiolipin in cytochrome c release from mitochondria. Cell Death Diff., 2007, 14, 1243-1247.

[4] Antonsson, B. Mitochondria and the $\mathrm{Bcl}-2$ proteins in apoptosis signaling pathways. Mol. Cell. Biochem., 2004, 256-257, 141-155.

[5] Schug, Z.T.; Frezza, C.; Galbraith, L.C.; Gottlieb, E. The music of lipids: how lipid composition orchestrates cellular behaviour. Acta Oncol., 2012, 51, 301-310.

[6] Chu, C.T.; Ji, J.; Dagda, R.K.; Jiang, J.F.; Tyurina, Y.Y.; Kapralov, A.A.; Tyurin, V.A.,; Yanamala, N.; Shrivastava, I.H.; Mohammadyani, D.; Qiang, W.K.Z.; Zhu, J.; Klein-Seetharaman, J.; Balasubramanian, K.; Amoscato, A.A.; Borisenko, G., Huang, Z.; Gusdon, A.M., Cheikhi, A.; Steer, E.K.; Wang, R.; Baty, C.; Watkins, S.; Bahar, I.; Bayır, H.; Kagan, V.E. Cardiolipin externalization to the outer mitochondrial membrane acts as an elimination signal for mitophagy in neuronal cells. Nat. Cell. Biol., 2013, 15, 1197-1205.

[7] Schlame, M.; Rua, D.; Greenberg, M.L. The biosynthesis and functional role of cardiolipin. Prog. Lipid Res., 2000, 39, 257-288. 
[8] Mileykovskaya, E.; Dowhan, W. Cardiolipin membrane domains in prokaryotes and eukaryotes. Biochim. Biophys. Acta, 2009, 1788, 2084-2091.

[9] Corcelli, A. The cardiolipin analogues of Archaea. Biochim. Biophys. Acta, 2009, 1788, 2101-2106.

[10] Ventrella, A.; Catucci, L.; Mascolo, G.; Corcelli, A.; Agostiano, A. Isolation and characterization of lipids strictly associated to PSII complexes: focus on cardiolipin structural and functional role. Biochim. Biophys. Acta, 2007, 1768, 1620-1627.

[11] Arias-Cartin, R.; Grimaldi, S.; Arnoux, P.; Guigliarelli, B.; Magalon, A. Cardiolipin binding in bacterial respiratory complexes: Structural and functional implications. Biochim. Biophys. Acta, 2012, 1817, 1937-1949.

[12] Christie, W.W.; Han, X. Lipid Analysis - Isolation, Separation, Identification and Lipidomic Analysis ( $4^{\text {th }}$ edition), 446 pages (Oily Press, Bridgwater, U.K. and Woodhead Publishing Ltd, Cambridge, U.K.) (2010) - Woodhead Publishing Ltd.

[13] Lewis, R.N.A.H.; McElhaney, R.N. The physicochemical properties of cardiolipin bilayers and cardiolipin-containing lipid membranes. Biochim. Biophys. Acta, 2009, 1788, 2069-2079.

[14] Schlame, M.; Ren, M. The role of cardiolipin in the structural organization of mitochondrial membranes. Biochim. Biophys. Acta, 2009, 1788, 2080-2083.

[15] Haines, T.H.; Dencher, N.A. Cardiolipin: a proton trap for oxidative phosphorylation. FEBS Lett., 2002, 528, 35-39.

[16] Mannella, C.A.; Lederer, W.J.; Jafri, M.S. The connection between inner membrane topology and mitochondrial function. J. Mol. Cell. Cardiol., 2013, 62C, 51-57.

[17] Houtkooper, R.H.; Vaz, F.M. Cardiolipin, the heart of the mitochondrial metabolism. Cell. Mol. Life Sci., 2008, 65, 2493-2506.

[18] Paradies, G.; Petrosillo, G.; Paradies, V.; Ruggiero, F.M. Role of cardiolipin peroxidation and $\mathrm{Ca}^{2+}$ in mitochondrial dysfunction and disease. Cell Calcium, 2009, 45, 643-650

[19] Haines, T.H.; Dencher, N.A. Cardiolipin: a proton trap for oxidative phosphorylation. FEBS Lett., 2002, 528, 35-39.

[20] Sharpley, M.S.; Shannon, R.J.; Draghi, F.; Hirst, J. Interactions between phospholipids and NADH: ubiquinone oxidoreductase (complex I) from bovine mitochondria. Biochemistry, 2006, 45, 241-248.

[21] Arnarez, C.; Mazat, J.P.; Elezgaray, J.; Marrink, S.J.; Periole, X. Evidence for cardiolipin binding sites on the membrane-exposed surface of the cytochrome bcl. J. Am. Chem. Soc., 2013, 135, 3112-3120.

[22] Pöyry, S.; Cramariuc, O.; Postila, P.A.; Kaszuba, K.; Sarewicz, M.; Osyczka, A.; Vattulainen, I.; Róg, T. Atomistic simulations indicate cardiolipin to have an integral role in the structure of the cytochrome bcl complex. Biochim. Biophys. Acta, 2013, 1827, 769778 .

[23] Arnarez, C.; Marrink, S.J.; Periole, X. Identification of cardiolipin binding sites on cytochrome $\mathrm{c}$ oxidase at the entrance of proton channels. Sci. Rep., 2013, 3, 1263.

[24] Acehan, D.; Malhotra, A.; Xu Y.; Ren, M.; Stokes, D.L.; Schlame, M. Cardiolipin affects the supramolecular organization of ATP synthase in mitochondria. Biophys. J., 2011, 100, 2184-2192.

[25] Klingenberg, M. Cardiolipin and mitochondrial carriers. Biochim. Biophys. Acta, 2009, 1788, 2048-2058.

[26] Rytömaa, M.; Kinnunen, P.K.J. Evidence for two distinct acidic phospholipids-binding sites in cytochrome c. J. Biol. Chem., 1994, 269, 1770-1774.

[27] Kalanxhi, E.; Wallace, C.J.A. Cytochrome $c$ impaled: investigation of the extended lipid anchorage of a soluble protein to mitochondrial membrane models. Biochem. J., 2007, 407, 179-187.

[28] Sinibaldi, F.; Howes, B.; Droghetti, E.; Polticelli, F.; Piro, M. C.; Di Pierro, D.; Fiorucci, L.; Coletta, M.; Smulevich, G.; Santucci R. Role of lysines in cytochrome c - cardiolipin interaction. Biochemistry, 2013, 52, 4578-4588.

[29] Schlattner, U.; Tokarska-Schlattner, M.; Ramirez, S.; Brückner, A.; Kay, L.; Polge, C.; Epand, R.F.; Lee, R.M.; Lacombe, M.L.; Epand, R.M. Mitochondrial kinases and their molecular interaction with cardiolipin. Biochim. Biophys. Acta, 2009, 1788, 2032-2047.

[30] Raja M. The role of phosphatidic acid and cardiolipin in stability of the tetrameric assembly of potassium channel KcsA. J. Membr. Biol., 2010, 234, 235-240.

[31] Beyer, K.; Klingenberg, M. ADP/ATP carrier protein from beef heart mitochondria has high amounts of tightly bound cardiolipin, as revealed by $31 \mathrm{P}$ nuclear magnetic resonance. Biochemistry, 1985, 24, 3821-3826.

[32] Claypool, S.M.; Oktay, Y.; Boontheung, P.; Loo, J.A.; Koehler, C.M. Cardiolipin defines the interactome of the major ADP/ATP carrier protein of the mitochondrial inner membrane. J. Cell. Biol., 2008, 182, 937-950.

[33] Claypool, S.M. Cardiolipin, a critical determinant of mitochondrial carrier protein assembly and function. Biochim. Biophys. Acta, 2009, 1788, 2059-2068.

[34] Stuart, R.A. Supercomplex organization of the oxidative phosphorylation enzymes in yeast mitochondria. J. Bioenerg. Biomembr., 2008, 40, 411-417.

[35] Vonck, J.; Scäfer, E. Supramolecular organization of protein complexes in the mitochondrial inner membrane. Biochim. Biophys. Acta, 2009, 1793, 117-124.

[36] Robinson, N.C. Functional binding of cardiolipin to cytochrome c oxidase. J. Bioenerg. Biomembr., 1993, 25, 153-163.

[37] Vartak, R.; Porras, C.A.; Bai, Y. Respiratory supercomplexes: structure, function and assembly. Protein Cell, 2013, 4, 582-590.

[38] Wenz, T.; Hielscher, R.; Hellwig, P.; Schägger, H.; Richers, S.; Hunte, C. Role of phospholipids in respiratory cytochrome bc(1) complex catalysis and supercomplex formation. Biochim. Biophys. Acta, 2009, 1787, 609-616.

[39] Böttinger, L.; Horvath, S.E.; Kleinschroth, T.; Hunte, C.; Daum, G.; Pfanner, N.; Becker, T. Phosphatidylethanolamine and cardiolipin differentially affect the stability of mitochondrial respiratory chain supercomplexes. J. Mol. Biol., 2012, 423, 677-686.

[40] Bazán, S.; Mileykovskaya, E.; Mallampalli, V.K.; Heacock, P.; Sparagna, G.C.; Dowhan, W. Cardiolipin-dependent reconstitution of respiratory supercomplexes from purified Saccharomyces cerevisiae complexes III and IV. J. Biol. Chem., 2013, 288, 401-411.

[41] Cadenas, E.; Davies, K.J. Mitochondrial free radical generation, oxidative stress, and aging. Free Radic. Biol. Med., 2000, 4, 222230 .

[42] Musatov, A.; Robinson, N.C. Susceptibility of mitochondrial electron-transport complexes to oxidative damage. Focus on cytochrome c oxidase. Free Radic. Res., 2012, 46, 1313-1326.

[43] Giulivi, C.; Poderoso, J.J.; Boveris, A. Production of nitric oxide by mitochondria. J. Biol. Chem., 1998, 273, 11038-11043.

[44] Rhee, S. G.; Kang, S. W.; Chang, T. S.; Jeong, W.; Kim, K. Peroxiredoxin, a novel family of peroxidases. IUBMB Life, 2001 52, 3541

[45] Miranda-Vizuete, A.; Damdimopoulos, A. E.; Spyrou, G. The mitochondrial thioredoxin system. Antioxid. Redox Signal., 2000, 2, 801-810.

[46] Bai, J.; Cederbaum, A. I. Mitochondrial catalase and oxidative injury. Biol. Signals Recept., 2001, 10, 189-199.

[47] Zhao, Y.; Wang, Z.B.; Xu, J.X. Effect of cytochrome $c$ on the generation and elimination of $\mathrm{O}_{2}^{-}$and $\mathrm{H}_{2} \mathrm{O}_{2}$ in mitochondria. $J$. Biol. Chem., 2003, 278, 2356-2360.

[48] Min, L.; Jian-xing, X. Detoxifying function of cytochrome $c$ against oxygen toxicity. Mitochondrion, 2007, 7, 13-16.

[49] Cai, H.; Harrison, D.G. Endothelial dysfunction in cardiovascular diseases: the role of oxidant stress. Circ. Res., 2000, 87, 840-844.

[50] Stadtman, E.R. Importance of individuality in oxidative stress and aging. Free Radic. Biol. Med., 2002, 33, 597-604.

[51] Victor, V.M.; Apostolova, N.; Herance, R.; Hernandez-Mijares, A; Rocha, M. Oxidative stress and mitochondrial dysfunction in atherosclerosis: mitochondria-targeted antioxidants as potential therapy. Curr. Med. Chem., 2009, 16, 4654-4667.

[52] Misra, M.K.; Sarwat, M.; Bhakuni, P.; Tuteja, R.; Tuteja, N. Oxidative and ischemic myocardial syndromes. Med. Sci. Monit., 2009, 15, RA209-RA219.

[53] Paradies, G.; Petrosillo, G.; Paradies, V.; Reiter, R.J.; Ruggiero, F.M. Melatonin, cardiolipin and mitochondrial bioenergetics in health and disease. J. Pineal Res., 2010, 48, 297-310.

[54] Cui, H.; Kong, Y.; Zhang, H. Oxidative Stress, Mitochondrial Dysfunction, and Aging. J. Signal Transduct., 2012, 2012, Art. 646354]

[55] Pamplona, R. Membrane phospholipids, lipoxidative damage and molecular integrity: a causal role in aging and longevity. Biochim. Biophys. Acta, 2008, 1777, 1249-1262.

[56] Sparagna, G.C.; Chicco, A.J.; Murphy, R.C.; Bristow, M.R.; Johnson, C.A.; Rees, M.L.; Maxey, M.L.; McCune, S.A.; Moore, R.L. Loss of cardiac tetralinoleoyl cardiolipin in human and experimental heart failure. J. Lipid Res., 2007, 48, 1559-1570. 
[57] Paradies, G.; Petrosillo, G.; Paradies, V.; Ruggiero, F.M. Mitochondrial dysfunction in brain aging: role of oxidative stress and cardiolipin. Neurochem. Int., 2011, 58, 447-457.

[58] Petrosillo, G.; De Benedictis, V.; Ruggiero, F.M.; Paradies, G. Decline in cytochrome $\mathrm{c}$ oxidase activity in rat-brain mitochondria with aging. Role of peroxidized cardiolipin and beneficial effect of melatonin. J. Bioenerg. Biomembr., 2013, 45, 431-440.

[59] Mok, A. Y. Comparative studies of CDP-diacylglycerol synthase in rat liver mitochondria and microsomes. Biochem. Cell Biol., 1993, $71,183-189$

[60] Tamura, Y.; Harada, Y.; Nishikawa, S.; Yamano, K.; Kamiya, M.; Shiota, T.; Kuroda, T.; Kuge, O.; Sesaki, H.; Imai, K.; Tomii, K.; Endo, T. Tam41 is a CDP-diacylglycerol synthase required for cardiolipin biosynthesis in mitochondria. Cell Metab., 2013, 17, 709718 .

[61] Kawasaki, K.; Kuge, O.; Chang, S.C.; Heacock, P.N.; Rho, M.; Suzuki, K.; Nishijima, M.; Dowan, W. Isolation of a chinese hamster ovary $(\mathrm{CHO})$ cDNA encoding phosphatidylglycerophosphate (PGP) synthase, expression of which corrects the mitochondrial abnormalities of a PGP synthase-defective mutant of CHO-K1 cells. J. Biol. Chem., 1999, 274, 1828-1834.

[62] Serricchio, M.; Bütikofer, P. Phosphatidylglycerophosphate synthase associates with a mitochondrial inner membrane complex and is essential for growth of Trypanosoma brucei. Mol. Microbiol., 2013, 87, 569-579.

[63] El-Kouhen, K.; Tremblay, M.L. PTPMT1: Connecting cardiolipin biosynthesis to mitochondrial function. Cell Metab., 2011, 13, 615617.

[64] Niemi, N.M.; Lanning, N.J.; Westrate1, L.M.; MacKeigan, J.P. Downregulation of the mitochondrial phosphatase PTPMT1 is sufficient to promote cancer cell death. PLoS One, 2013, 8, e53803.

[65] Schlame, M. Cardiolipin synthesis for the assembly of bacterial and mitochondrial membranes. J. Lipid Res., 2008, 49, 1607-1620.

[66] Mancuso, D.J.; Sims, H.F.; Yang, K.; Kiebish, M.A.; Su, X.; Jenkins, C.M.; Guan, S.; Moon, S.H.; Pietka, T.; Nassir, F.; Schappe, T.; Moore, K.; Han, X.; Abumrad, N.A.; Gross, R.W. Genetic ablation of calcium-independent phospholipase A2gamma prevents obesity and insulin resistance during high fat feeding by mitochondrial uncoupling and increased adipocyte fatty acid oxidation. J. Biol. Chem., 2010, 285, 36495-36510.

[67] Schlame, M.; Ren, M.; Xu, Y.; Greenberg, M.L.; Haller, I. Molecular symmetry in mitochondrial cardiolipins. Chem. Phys. Lipids, 2005, 138, 38-49.

[68] Claypool, S.M.; Koehler, C.M. The complexity of cardiolipin in health and disease. Trends Biochem. Sci., 2012, 37, 32-41.

[69] Schlame, M.; Acehan, D.; Berno, B.; Xu, Y.; Valvo, S.; Ren M.; Stokes, D.L.; Epand, R.M. The physical state of lipid substrates provides transacylation specificity for tafazzin. Nat. Chem. Biol., 2012, 8, 862-869.

[70] Taylor, W.A.; Hatch, G.M. Identification of the human mitochondrial linoleoyl-coenzyme A monolysocardiolipin acyltransferase (MLCL AT-1). J. Biol. Chem., 2009, 284, 30360-30371.

[71] Patil, V.A.; Greenberg, M.L. Cardiolipin-mediated cellular signaling. Adv. Exp. Med. Biol., 2013, 991, 195-213.

[72] Saini-Chohan, H. K.; Holmes, M.G.; Chicco, A.J.; Taylor, W.A.; Moore, R.L.; McCune, S.A.; Hickson-Bick, D.L.; Hatch, G.M.; Sparagna, G.C. Cardiolipin biosynthesis and remodeling enzymes are altered during development of heart failure. J. Lipid Res., 2009, $50,1600-1608$.

[73] He, Q.; Han, X. Cardiolipin remodeling in diabetic heart. Chem. Phys. Lipids, 2014, 179, 75-81.

[74] Taylor, W.A.; Mejia, E.M.; Mitchell, R.W.; Choy, P.C.; Sparagna, G.C.; Hatch, G.M. Human trifunctional protein alpha links cardiolipin remodeling to beta-oxidation. PLoS One, 2012, 7, e48628.

[75] Gebert, N.; Joshi, A.S.; Kutik, S.; Becker, T.; McKenzie, M.; Guan, X.L.; Mooga, V.P.; Stroud, D.A.; Kulkarni, G.; Wenk, M.R.; Rehling, P.; Meisinger, C.; Ryan, M.T.; Wiedemann, N.; Greenberg, M.L.; Pfanner, N. Mitochondrial cardiolipin involved in outermembrane protein biogenesis: implications for Barth syndrome. Curr. Biol., 2009, 19, 2133-2139.

[76] Dzugasová, V.; Obernauerová, M.; Horváthová, K.; Vachová, M.; Záková, M.; Subík, J. Phosphatidylglycerolphosphate synthase encoded by the PEL1/PGS1 gene in Saccharomyces cerevisiae is localized in mitochondria and its expression is regulated by phospholipid precursors. Curr. Genet., 1998, 34, 297-302.
[77] Osman, C.; Haag, M.; Wieland, F.T.; Brügger, B.; Langer, T. A mitochondrial phosphatase required for cardiolipin biosynthesis: the PGP phosphatase Gep4. EMBO J., 2010, 29, 1976-1987.

[78] Van, Q.; Liu, J.; Lu, B.; Feingold, K.R.; Shi, Y.; Lee, R.M.; Hatch, G.M. Phospholipid scramblase-3 regulates cardiolipin de novo biosynthesis and its resynthesis in growing HeLa cells. Biochem. J., 2007, 401, 103-109.

[79] Maniti, O.; Lecompte, M.F.; Marcillat, O.; Desbat, B.; Buchet, R.; Vial, C.; Granjon, T. Mitochondrial creatine kinase binding to phospholipid monolayers induces cardiolipin segregation. Biophys. J., 2009, 96, 2428-2438.

[80] Kiebish, M.A.; Han, X.; Cheng, H.; Chuang, J.H.; Seyfried, T.N. Brain mitochondrial lipid abnormalities in mice susceptible to spontaneous gliomas. Lipids, 2008, 43, 951-959.

[81] Cheng, H.; Mancuso, D.J.; Jiang, X.; Guan, S.; Yang, J.; Yang, K.; Sun, G.; Gross, R.W.; Han, X. Shotgun lipidomics reveals the temporally dependent, highly diversified cardiolipin profile in the mammalian brain: temporally coordinated postnatal diversification of cardiolipin molecular species with neuronal remodeling. Biochemistry, 2008, 47, 5869-5880.

[82] Vaughn, A.E.; Deshmukh, M. Glucose metabolism inhibits apoptosis in neurons and cancer cells by redox inactivation of cytochrome c. Nat. Cell Biol., 2008, 10, 1477-1483.

[83] Chu, C.T.; Bayır, H.; Kagan, V.E. LC3 binds externalized cardiolipin on injured mitochondria to signal mitophagy in neurons: Implications for Parkinson disease. Autophagy, 2014, 10, 376-378.

[84] de Vries, R.L.; Przedborski, S. Mitophagy and Parkinson's disease: be eaten to stay healthy. Mol. Cell. Neurosci., 2013, 55, 37-43.

[85] Williams, T.L.; Serpell, L.C. Membrane and surface interactions of Alzheimer's $\mathrm{A} \beta$ peptide--insights into the mechanism of cytotoxicity. FEBS J., 2011, 278, 3905-3917.

[86] Tofoleanu, F.; Buchete, N.V. Alzheimer A $\beta$ peptide interactions with lipid membranes: fibrils, oligomers and polymorphicamyloid channels. Prion, 2012, 6, 339-345.

[87] Oliveira, L.M.; Gomes, R.A.; Yang, D.; Dennison, S.R.; Família, C.; Lages, A.; Coelho, A.V.; Murphy, R.M.; Phoenix, D.A.; Quintas, A. Insights into the molecular mechanism of protein native-like aggregation upon glycation. Biochim. Biophys. Acta, 2013 , 1834, 1010-1022.

[88] Eidelberg, D.; Martin, W. Different $\beta$-amyloid binding patterns in Alzheimer and Parkinson diseases: It's the network! Neurology, 2013, 81, 516-517.

[89] Camilleri, A., Zarb, C.; Caruana, M.; Ostermeier, U.; Ghio, S.; Högen, T.; Schmidt, F.; Giese, A.; Vassallo, N. Mitochondrial membrane permeabilisation by amyloid aggregates and protection by polyphenols. Biochim. Biophys. Acta, 2013, 1828, 2532-2543.

[90] Nagakawa, Y. Initiation of apoptotic signal by the peroxidation of cardiolipin of mitochondria. Ann. N.Y. Acad. Sci., 2004, 1011, 177184.

[91] Kapralov, A. A.; Kurnikov, I. V.; Vlasova, II; Belikova, N. A.; Tyurin, V. A.; Basova, L.V.; Zhao, Q.; Tyurina, Y. Y.; Jiang, J.; Bayir, H.; Vladimirov, Y. A.; Kagan, V. E. The hierarchy of structural transitions induced in cytochrome $c$ by anionic phospholipids determines its peroxidase activation and selective peroxidation during apoptosis in cell. Biochemistry, 2007, 46, 14232-14244.

[92] Kagan, V.E.; Bayır, H.A.; Belikova, N.A.; Kapralov, O.; Tyurina, Y.Y.; Tyurin, V.A.; Jiang, J.; Stoyanovsky, D.A.; Wipf, P.; Kochanek, P.M.; Greenberger, J.S.; Pitt, B.; Shvedova, A.A.; Borisenko, G. Cytochrome $c$ /cardiolipin relations in mitochondria: a kiss of death. Free Radic. Biol. Med., 2009, 46, 1439-1453.

[93] Patriarca, A.; Polticelli, F.; Piro, M.C.; Sinibaldi, F.; Mei, G.; Bari, M.; Santucci, R.; Fiorucci L. Conversion of cytochrome $\mathrm{c}$ into a peroxidase: inhibitory mechanisms and implication for neurodegenerative diseases. Arch. Biochem. Biophys., 2012, 522, 62-69.

[94] Gatenby, R.A.; Gillies, R. J. Why do cancers have high aerobic glycolysis? Nat. Rev. Cancer, 2004, 4, 891-899.

[95] Barbosa, A.; Machado, N.G.; Skildum, A.J.; Scott, P.M.; Oliveira, P.J. Mitochondrial remodeling in cancer metabolism and survival: potential for new therapies. Biochim. Biophys. Acta, 2012, 1826, 238-254.

[96] Kiebish, M.A.; Han, X.; Cheng, H.; Chuang, J.H.; Seyfried, T.N. Cardiolipin and electron transport chain abnormalities in mouse brain tumor mitochondria: lipidomic evidence supporting the Warburg theory of cancer. J. Lipid Res., 2008, 49, 2545-2556. 
[97] Dumas, J-F.; Peyta, L.; Couet, C.; Servais S. Implication of liver cardiolipins in mitochondrial energy metabolism disorder in cancer cachexia. Biochimie, 2013, 95, 27-32.

[98] Barth, P.G.; Wanders, R.J.; Vreken, P. X-linked cardioskeletal myopathy and neutropenia (Barth syndrome)-MIM 302060. J. Pediatr., 1999, 135, 273-276.

[99] Vreken, P.; Valianpour, F.; Nijtmans, L.G.; Grivell, L.A.; Plecko, B.; Wanders, R.J.; Barth, P.G. Defective remodeling of cardiolipin and phosphatidylglycerol in Barth syndrome. Biochem. Biophys. Res. Commun., 2000, 279, 378-382.

[100] Gonzalvez, F.; D'Aurelio, M.; Boutant, M.; Moustapha, A.; Puech, J.P.; Landes, T.; Arnauné-Pelloquin, L.; Vial, G.; Taleux, N.; Slomianny, C.; Wanders, R.J.; Houtkooper, R.H.; Bellenguer P.; Møller, I.M.; Gottlieb, E.; Vaz, F.M.; Manfredi, G.; Petit, P.X. Barth syndrome: Cellular compensation of mitochondrial dysfunction and apoptosis inhibition due to changes in cardiolipin remodeling linked to tafazzin (TAZ) gene mutation. Biochim. Biophys. Acta, 2013, 1832, 1194-1206.

[101] Tamura, Y.; Endo, T. Unveiling the last missing link of the cardiolipin synthetic pathway in mitochondria. Aging, 2013, 5, 392-393.

[102] Smith, D.J.; Ng, H.; Kluck, R.M.; Nagley, P. The mitochondrial gateway to cell death. IUBMB Life, 2008, 60, 383-389.

[103] Caroppi, P.; Sinibaldi, F.; Fiorucci, L.; Santucci, R. Apoptosis and human diseases: mitochondrion damage and lethal role of cytochrome c as proapoptotic protein. Curr. Med. Chem., 2009, 16, 4058-4065.

[104] Schug, Z.T.; Gottlieb, E. Cardiolipin acts as a mitochondrial signalling platform to launch apoptosis. Biochim. Biophys. Acta, 2009, 1788, 2022-2031.

[105] Ascenzi, P.; Polticelli, F.; Marino, M.; Santucci, R.; Coletta, M. Cardiolipin drives cytochrome c pro- and anti-apoptotic actions. IUBMB Life, 2011, 63, 160-165.

[106] Estaquier, J.; Vallette, F.; Vayssiere, J.L.; Mignotte, B. The mitochondrial pathways of apoptosis. Adv. Exp. Med. Biol., 2012, 942, 157-183.

[107] Pettigrew, G. W.; Moore, G. R. Cytochromes c. Biological aspects. Springer-Verlag: Heidelberg, 1987.

[108] Bayir, H.; Fadeel, B.; Palladino, M. J.; Witasp, E.; Kurnikov, I. V.; Tyurina, Y.Y.; Tyurin, V. A.; Amoscato, A.A.; Jiang, J.; Kochanek, P.M.; DeKosky, S.T.; Greenberger, J.S.; Shvedova, A.A.; Kagan, V. E. Apoptotic interactions of cytochrome $c$ : redox flirting with anionic phospholipids within and outside of mitochondria. Biochim. Biophys. Acta, 2006, 1757, 648-659.

[109] Hüttemann, M.; Pecina, P.; Rainbolt, M.; Sanderson, T.H.; Kagan, V.E.; Samavati, L.; Doan, J.W.; Lee, I. The multiple functions of cytochrome $\mathrm{c}$ and their regulation in life and death decisions of the mammalian cell: From respiration to apoptosis. Mitochondrion, 2011, 11, 369-381.

[110] Hüttemann, M.; Lee, I.; Grossman, L.I.; Doan, J.W.; Sanderson, T.H. Phosphorylation of mammalian cytochrome c and cytochrome c oxidase in the regulation of cell destiny: respiration, apoptosis, and human disease. Adv. Exp. Med. Biol., 2012, 748, 237-264.

[111] Nagakawa, Y. Initiation of apoptotic signal by the peroxidation of cardiolipin of mitochondria. Ann. N.Y. Acad. Sci., 2004, 1011, 177184.

[112] Kapralov, A. A.; Kurnikov, I. V.; Vlasova, II; Belikova, N. A.; Tyurin, V. A.; Basova, L.V.; Zhao, Q.; Tyurina, Y. Y.; Jiang, J.; Bayir, H.; Vladimirov, Y. A.; Kagan, V. E. The hierarchy of structural transitions induced in cytochrome $c$ by anionic phospholipids determines its peroxidase activation and selective peroxidation during apoptosis in cell. Biochemistry, 2007, 46, 14232-14244.

[113] Kagan, V.E.; Bayır, H.A.; Belikova, N.A.; Kapralov, O.; Tyurina, Y.Y.; Tyurin, V.A.; Jiang, J.; Stoyanovsky, D.A.; Wipf, P.; Kochanek, P.M.; Greenberger, J.S.; Pitt, B.; Shvedova, A.A.; Borisenko, G. Cytochrome $c /$ cardiolipin relations in mitochondria: a kiss of death. Free Radic. Biol. Med., 2009, 46, 1439-1453.

[114] Ott, M.; Zhivotovsky, B.; Orrenius, S. Role of cardiolipin in cytochrome c release from mitochondria. Cell Death Diff., 2007, 14, 1243-1247.

[115] Sinibaldi, F.; Fiorucci, L.; Patriarca, A.; Lauceri, R.; Ferri, T.; Coletta, M.; Santucci, R. Insights into cytochrome c-cardiolipin interaction. Role played by ionic strength. Biochemistry, 2008, 47, 6928-6935.

[116] Rytömaa, M.; Kinnunen, P.K.J. Reversibility of the binding of cytochrome c liposomes. Implications for lipid-protein interactions. J. Biol. Chem, 1995, 270, 3197-3202.
[117] Sinibaldi, F.; Howes, B.D.; Piro, M.C.; Polticelli, F.; Bombelli, C.; Ferri, T.; Coletta, M.; Smulevich, G.; Santucci R. Extended cardiolipin anchorage to cytochrome c: a model for proteinmitochondrial membrane binding. J. Biol. Inorg. Chem., 2010, 15, 689-700.

[118] Rajagopal, B.S.; Silkstone, G.G.; Nicholls, P.; Wilson, M.T.; Worrall, J.A. An investigation into a cardiolipin acyl chain insertion site in cytochrome c. Biochim. Biophys. Acta, 2012, 1817, 780791.

[119] Kawai, C; Prado, F.M.; Nunes, G.L.C.; Di Mascio, P.; CarmonaRibeiro, A.M.; Nantes, I.L. pH- dependent interaction of cytochrome c with mitochondrial mimetic membranes. The role of an array of positively charged amino acids. J. Biol. Chem., 2005, 280, 34709-34717.

[120] Hong, Y.; Muenzner, J.; Grimm, S.K.; Pletneva, E.V. Origin of the conformational heterogeneity of cardiolipin-bound cytochrome c. $J$. Am. Chem. Soc., 2012, 134, 18713-18723.

[121] Hanske, J.; Toffey, J.R.; Morenz, A.M.; Bonilla, A.J., Schiavoni, K.H.; Pletneva, E.V. Conformational properties of cardiolipinbound cytochrome c. Proc. Natl. Acad. Sci. USA, 2012, 109, 125130 .

[122] Macchioni, L.; Davidescu, M.; Mannucci, R.; Francescangeli, E.; Nicoletti, I.; Roberti, R.; Corazzi, L. $\mathrm{H}_{2} \mathrm{O}_{2}$ disposal in cardiolipinenriched brain mitochondria is due to increased cytochrome c peroxidase activity. Biochim. Biophys. Acta, 2011, 181, 203-208.

[123] Belikova, N.A.; Vladimirov, Y,A.; Osipov, A,N.; Kapralov, A,A.; Tyurin, V,A.; Potapovich, M.V.; Basova, L.V.; Peterson, J.; Kurnikov, I.V.; Kagan, V.E. Peroxidase activity and structural transitions of cytochrome $c$ bound to cardiolipin-containing membranes. Biochemistry, 2006, 45, 4998-5009.

[124] Diederix, R. E.; Ubbink, M; Canters, G. W. Peroxidase activity as a tool for studying the folding of c-type cytochromes. Biochemistry, 2002, 41, 13067-13077.

[125] Patriarca, A.; Eliseo, T.; Sinibaldi, F.; Piro, M.C.; Melis, R.; Paci, M.; Cicero, D.O.; Polticelli, F.; Santucci R.; Fiorucci L. ATP acts as a regulatory effector in modulating structural transitions of cytochrome c: implications for apoptotic activity. Biochemistry, 2009, 48, 3279-3287.

[126] Korytowski, W.; Basova, L.V.; Pilat, A.; Kernstock, R.M.; Girotti, A.W. Permeabilization of the mitochondrial outer membrane by $\mathrm{Bax} /$ truncated Bid (tBid) proteins as sensitized by cardiolipin hydroperoxide translocation: mechanistic implications for the intrinsic pathway of oxidative apoptosis. J. Biol. Chem., 2011, 286, 2633426343.

[127] Min, L.; Jian-xing, X. Detoxifying function of cytochrome c against oxygen toxicity. Mitochondrion, 2007, 7, 13-16.

[128] Everse, J.; Liu, C.J.; Coates, P.W. Physical and catalytic properties of a peroxidase derived from cytochrome c. Biochim. Biophys. Acta, 2011, 1812, 1138-1145.

[129] Kagan, V.E.; Bayir, A.; Bayir, H.; Stoyanovsky D.; Borisenko G.G.; Tyurina Y.Y.; Wipf P.; Atkinson, J.; Greenberger J.S. ; Chapkin, R.S.; Belikova, N.A. Mitochondria-targeted disruptors and inhibitors of cytochrome $c$ /cardiolipin peroxidase complexes: A new strategy in anti-apoptotic drug discovery. Mol. Nutr. Food Res., 2009, 53, 104-114.

[130] Kale, J.; Liu, Q.; Leber, B.; Andrews DW. Shedding light on apoptosis at subcellular membranes. Cell, 2012, 151, 1179-1184.

[131] Lindsay, J.; Esposti, M.D.; Gilmore, A.P. Bcl-2 proteins and mitochondria-specificity in membrane targeting for death. Biochim. Biophys. Acta, 2011, 1813, 532-539.

[132] Shamas-Din, A.; Bindner, S.; Zhu, W.; Zaltsman, Y.; Campbell, C.; Gross, A.; Leber, B.; Andrews, D.W.; Fradin, C. tBid Undergoes Multiple Conformational Changes at the Membrane Required for Bax Activation. J. Biol. Chem., 2013, 288, 22111-22127.

[133] Wallach, D.; Varfolomeev, E.E.; Malinin, N.L.; Goltsev, Y.V.; Kovalenko, A.V.; Boldin M.P. Tumor necrosis factor receptor and Fas signaling mechanisms. Ann. Rev. Immunol., 1999, 17, 331-367.

[134] Zhang, T.; Saghatelian, A. Emerging roles of lipids in BCL-2 family-regulated apoptosis. Biochim. Biophys. Acta, 2013, 1831, 15421554.

[135] Wasilewski, M.; Scorrano, L. The changing shape of mitochondrial apoptosis. Trends Endocrinol. Metab., 2009, 20, 287-294.

[136] Gonzalvez, F.; Pariselli, F.; Jalmar, O.; Dupaigne, P.; Sureau, F.; Dellinger, M.; Hendrickson, E.A.; Bernard, S.; Petit, P.X. Mechanistic issues of the interaction of the hairpin-forming domain of tBid with mitochondrial cardiolipin. PLoS One, 2010, 5, e9342. 
[137] Raemy, E.; Martinou, J.C. Involvement of cardiolipin in tBIDinduced activation of BAX during apoptosis. Chem. Phys. Lipids, 2014, 179, 70-74.

[138] Cho, E.I.; Yun, C.H.; Ahn, T. Effects of phospholipids on the functional regulation of tBID in membranes. Mol. Cell. Biochem., 2012, 363, 395-408.

[139] Lutter, M.; Fan, M.; Luo, X.; Nishijima, M.; Xie, X.; Wang, X. Cardiolipin provides specificity for targeting of tBid to mitochondria. Nat. Cell. Biol., 2000, 2, 754-761.

[140] Frezza, C.; Cipolat, S.; Martins de Brito, O.; Micaroni, M.; Beznoussenko, G.V.; Rudka, T.; Bartoli, D.; Polishuck, R.S.; Danial, N.N.; De Strooper, B.; Scorrano, L. OPA1 controls apoptotic cristae remodeling independently from mitochondrial fusion. Cell, 2006, 126, 177-189.

Received: September 20, 2013

Revised: February 04, 2014

Accepted: April 10, 2014
[141] Yamaguchi, R.; Lartigue, L.; Perkins, G.; Scott, R.T.; Dixit, A.; Kushnareva, Y.; Kuwana, T.; Ellisman, M.H.; Newmeyer, D.D. Opal-mediated cristae opening is Bax/Bak and $\mathrm{BH} 3$ dependent, required for apoptosis, and independent of Bak oligomerization. Mol. Cell., 2008, 31, 557-569.

[142] Lovell, J.F.; Billen, L.P.; Bindner, S.; Shamas-Din, A; Fradin, C.; Leber, B.; Andrews, D.W. Membrane binding by tBid initiates an ordered series of events culminating in membrane permeabilization by Bax. Cell, 2008, 135, 1074-1084.

[143] Pettersen, E. F.; Goddard, T. D.; Huang, C. C.; Couch, G. S.; Greenblatt, D. M.; Meng, E. C.; Ferrin, T. E. UCSF Chimera visualization system for exploratory research and analysis. J. Comput. Chem., 2004, 25, 1605-1612. 